\title{
In situ acoustic analysis of two twentieth-century heritage carillons
}

Scott Allan Orr

\begin{abstract}
Carillons are a diverse and global form of musical and civic heritage: musical instruments comprised of a series of 23 or more bells, typically hung in a tower-like structure, tuned chromatically and played from a touch-sensitive manual and pedal console using an elaborate mechanical action. Carillon bells have a distinct series of musical overtones which should be accurately tuned to one another and with other bells they sound alongside. Although these overtones have been previously studied ex situ, this study assesses the acoustic characteristics of two early-twentieth century carillons in Toronto, Canada as a combination of structure, bells, and mechanical action. Thus, the instrument and its context are considered holistically, more accurately reflecting the musical sensitivity of a carillonist. Spectral analysis of audio samples of each bell at different musical dynamic levels enabled the analysis of the acoustic qualities of the bells and the mechanical action of the instruments. The tuning of bells in the instruments varied; most importantly, there was a significant difference between the audial intensity of the bell tones produced by the instruments, demonstrating the importance of the mechanical action as part of the 'carillon system'. This was represented with a resistive power-law model, that represents the sensitivity of intensity to carillonist musical dynamic level. A discussion of the implications for artistic and heritage practice follows. Understanding the in situ physical acoustics of the carillon as a holistic instrument in its context informs performers, arrangers, and composers of how they can best embrace the instrument's unique qualities to improve artistic pursuits and support the appreciation of carillons as heritage instruments and function as civic voices.
\end{abstract}

Keywords: Musical heritage, Bells, Bell tuning, Historic instruments

\section{Introduction}

A carillon (derived from the French; Dutch: beiaard; German: glokenspiel) is "a series of at least 23 tuned bells, played from a keyboard that allows expressiveness through variation in touch" [1] that may be transposed. A standard carillon generally includes four chromatic octaves (about 49 bells), which vary in weight from many tonnes to a few kilograms. The bells are operated from a console comprised of a series of wooden keys ('batons'), arranged over two rows in a typical keyboard configuration, and a pedalboard that doubles up the control of some of the largest bells (typically one and half to two octaves).

*Correspondence: scott.orr@ucl.ac.uk

Institute for Sustainable Heritage, University College London, 14 Upper Woburn PI, London WC1H ONN, UK
Many carillons are important heritage landmarks and are an integral part of local community identity and culture. In the Low Countries where the instrument originated, 56 belfries of Belgium and France have been collectively inscribed as a World Heritage Site since 1999 (expanded in 2005) [2]. Their outstanding universal value is derived from their representation of the winning of civic liberties and testimony to a range of architectural styles prevalent from the eleventh to seventeenth centuries. The instruments and their towers have become a strong component of regional cultural identity. More recently, under the Convention for the Safeguarding of the Intangible Cultural Heritage [3] there has been a programme to safeguard the carillon culture that exists in seventy-six cities and villages of Belgium and in thirty countries worldwide [4]. In the twenty-first century,
Springer Open

(c) The Author(s) 2021. This article is licensed under a Creative Commons Attribution 4.0 International License, which permits use, sharing adaptation, distribution and reproduction in any medium or format, as long as you give appropriate credit to the original author(s) and the source, provide a link to the Creative Commons licence, and indicate if changes were made. The images or other third party material in this article are included in the article's Creative Commons licence, unless indicated otherwise in a credit line to the material. If material is not included in the article's Creative Commons licence and your intended use is not permitted by statutory regulation or exceeds the permitted use, you will need to obtain permission directly from the copyright holder. To view a copy of this licence, visit http://creativeco mmons.org/licenses/by/4.0/. The Creative Commons Public Domain Dedication waiver (http://creativecommons.org/publicdomain/ zero/1.0/) applies to the data made available in this article, unless otherwise stated in a credit line to the data. 
carillons have become strong voices for fostering equality, diversity, and inclusion in communities [5].

While the structures in which the instruments are housed present complex challenges to heritage management, additional challenges are posed by the nature of carillons as mechanical instruments. Although no robust study has been undertaken, formal and informal protection is generally given to the bells within the instrument. Due to this, many carillons dating from the seventeenth to twentieth centuries are still comprised of several of the bells originally installed in the instruments. Over the course of the twentieth century several technical innovations improved the control a carillonist had over the musical capabilities of the instruments. These were primarily improvements in the mechanical action and fabrication techniques for bells that expanded the typical range of the instruments compared to their historical precedents during earlier centuries. Due to this, mechanical actions of carillon instruments have frequently been upgraded and replaced with little care of their potential heritage value. Research on preserving original integrity and material of carillons is typically limited to the bells themselves [6]. Thus, material value is ascribed to only part of the instrument. Instead, emphasis is placed on the intangible heritage value and role of the carillon as an instrument with a civic voice, which necessitates the technical improvements of the instrument to enable a modern standard of artistic performance. While the preservation of material authenticity has been discussed in depth by restorers of other instruments (e.g. organs [7]), and many challenges have been identified for heritage instruments more broadly [8], discussion about the conservation and restoration of heritage carillons has been very limited.

Composing and arranging musical compositions for the carillon is complicated by:

- a lack of damping mechanisms,

- extended, but varied sound decay periods,

- the complex, prominent overtones associated with each bell.

Many introductory guides have been published to encourage and aid composers interested in the instrument [9-12] and more recently [13], although these focus on the physical limitations of the player and the mechanism and do not provide detailed information on the overtones (referred to as partials) and sound decay rates/periods. Those that do mention partials [14, 15] do not elaborate beyond the prominent minor third, except for the video component of the former and one that discusses the first 7 partials [16]. There have also been unpublished lectures on the topic (e.g. [17]).
Gerken provides excellent examples of thinning out texture while retaining harmonic structure [18] for arrangement and transcription purposes. On the whole, these guides are based on experiential practice of playing the carillon and composing and arranging music for the instrument.

This lack of literature is-in part-due to a lack of scientific documentation on in situ acoustics of carillon bells. The authoritative texts on carillon bell acoustics were undertaken in isolated conditions and utilise standardised mechanical strikes to initiate sound [19-21]. This is strikingly different to the informed touch of the experienced carillonist, who adapts the input force depending on the response from the weight of a clapper to produce a balanced sound landscape. Thus, the perceivable acoustic character of bells in the instrument is different in situ than in controlled experimental conditions. One exception is [22], who characterise modal frequency, exponential decay rate, and initial complex amplitude from audio samples taken in situ; it is notable that the decay rates are analysed in the context of the non-neglible ambient noise of the campus environment. However, these samples do not represent the dynamic musical input of a carillonist.

Although bellfounding has incorporated technologies as they have become available (such as 3D scanning [23]), it still incorporates elements of a traditional craft. Each carillon bell cast-especially those fabricated prior to electronic frequency analysers-possesses a unique sound colour based on the balance of the frequencies produced and their relative intensities. In contrast to the landmark work published by Lehr in 1951 [24] that focuses on seventeenth-century instruments, this study analyses twentieth-century instruments founded with modern techniques. Notably, these instruments were tuned with a mechanical lathe but without electronic analysis.

This study investigates the physical attributes of two heritage carillons in Toronto, Canada, and subsequently applies spectral analysis to analyse the in situ frequency and sound intensity of the five primary overtones at different musical dynamic levels. Testing the acoustic characteristics of the bells in situ means that the transmission system (the mechanical action) is considered as an integral component of the instrument, which can greatly impact its musical capabilities. This study identifies characteristics that are relevant to carillon performance and composition by analysing the sounds produced by the bells from within the belfry. In contrast with established methods in the field that remove the bells from the tower structures and analyse them in acoustic isolation, this method thus employs an innovative approach by analysing the carillon as a composite musical instrument comprised of its structure, a set of bells, and mechanical 
action, in the context of its common role as both tangible heritage and civic voice.

\section{Carillon characteristics Mechanism}

The carillon console is comprised of a single manual of wooden batons [25] with pedals located at foot-level of the console, which approximately double the lowest two octaves of the manuals. The manuals are generally played by striking the baton with a closed fist. The considerable weight of the larger clappers (the size of which vary according to the size of the respective bell) means agile playing within this part of the instrument is executed more easily with the pedals rather than the manual, due to the increase in available inertia from the weight of the leg. Clapper weights, relative to the mass of the associated bells, differ greatly between sources-most likely due to foundry practices and instrument variations ([26], p. 112) ([27], p. 46) [28].

The transmission wires extend through the floor and ceiling of the playing cabin or space. A common type of connection between the transmission lines and the clapper wires in twentieth-century instruments is a transmission bar ([27], p. 81-83): a long metal cylinder that rotates axially that can pull a clapper wire located in a remote horizontal position of the belfry. Depressing a baton puts this system into action, which bring the clapper into contact with the interior rim of the bell. Crucially, the dimensions of connections between the console can vary for sets of bells, or for each bell individually. Each clapper is also equipped with a sensitive adjuster that modifies the wire length between baton and clapper to accommodate for changes in the dimensions of the metal components due to changes in temperature.

To control the force with which the clapper comes into contact with the bell, carillonists develop a technique to 'prepare' a note: sufficient force is applied to depress the key to a certain depth such that the the clapper does not make contact with the bell. From this position the performer determines the volume of the bell strike by varying a torque-like flick of the wrist or ankle. Depressing the respective appendage results in a very dull, soft tone, while a quick action transmits greater speed and force to the clapper to produce louder dynamics.

The time-dependent force exerted by the clapper on the bell can be represented by a sphere impacting a very massive plate $[29,30]$. The force gradient is dependent on the Poisson's ratios ${ }^{1}(\mu)$ and Young's moduli ${ }^{2}(\mathrm{E})$ of the

\footnotetext{
${ }^{1}$ The ratio of transverse contraction strain to longitudinal extension strain in the direction of stretching force.

${ }^{2}$ Measure of the stiffness of an elastic material; obtainable from the slope of the linear portion of a stress-strain curve.
}

clapper $\delta_{1}$ and the bell $\delta_{2}$, the clapper parameters: radius, $r$, mass $m$, and impact velocity $v$.

$$
F \approx 0.44 \frac{m^{3 / 5} r^{1 / 2} v^{6 / 5}}{\delta_{1}+\delta_{2}} \sin \left(\pi t / \tau_{H}\right)
$$

where $\delta_{i}=f\left(E_{i}, \mu_{i}\right)$, and $\tau_{H}$ is the contact time $=f\left(\delta_{1,2}, m, r, v\right)$.

Separating the amplitude and temporal components of this relationship, at the point of maximum bell deflection

$$
F_{\max } \approx 0.44 \frac{m^{3 / 5} r^{1 / 2} v^{6 / 5}}{\delta_{1}+\delta_{2}}
$$

for any given bell in a carillon with known dimensions (and assuming negligible changes in $m, r$, and $\delta_{i}$ due to the effects of weather or oxidation), we can then directly relate the force and the overall sound decay $\left(\sin \left(\pi t / \tau_{H}\right)\right)$ to the velocity of the strike force with a constant proportionality coefficient, ie.

$$
F_{\text {player }} \propto F_{\text {max }} \approx\left(0.44 \frac{m^{3 / 5} r^{1 / 2}}{\delta_{1}+\delta_{2}}\right) v^{6 / 5}
$$

This means that, for each bell, the force exerted by striking of the clapper is only dependent on the velocity of the baton strike by the player.

\section{Acoustic characteristics of bells}

When struck by its clapper, a bell is distorted and then vibrates in a complex manner [31]. The vibration can be described as the combination of several 'modes' of vibration around a number of stationary lines around the circumference of the bell ('nodal meridians') and along the length of the body ('nodal circles'). The observed frequencies (also referred to as partials) are normally grouped into families based on similar properties. The relative prominence of a partial is dependent on the location and other details of the clapper strike. The most important families of partials are those with an antinode (places where the bell wall vibrates at a maximum) nearest to the clapper strike [32]. The first five modes of a bell are often referred to by descriptive/colloquial names, and fall within two families:

- those in Group 1 (the hum, the tierce, and the nominal) with an antinode near to the sound bow, and

- those in Group 2 (the fundamental and the quint) with an antinode near the waist of the bell as a result of the entire bell's vibration.

The number and location of these modes for the first five partials of a tuned European bell are presented in Table 1 . 
Table 1 Characteristics of the modes of the primary partials within a well-tuned European bell [33]

\begin{tabular}{lll}
\hline Name & $\begin{array}{l}\text { Number of nodal } \\
\text { meridians }\end{array}$ & $\begin{array}{l}\text { Number } \\
\text { and position } \\
\text { of nodal } \\
\text { circles }\end{array}$ \\
\hline Hum & 4 & 0 \\
Fundamental & 4 & $\begin{array}{c}1 \text { (between } \\
\text { the rim and } \\
\text { the waist) }\end{array}$ \\
Tierce & 6 & 1 (in waist) \\
Quint & 6 & 1 (near rim) \\
Nominal & 8 & 1 (in waist) \\
\hline
\end{tabular}

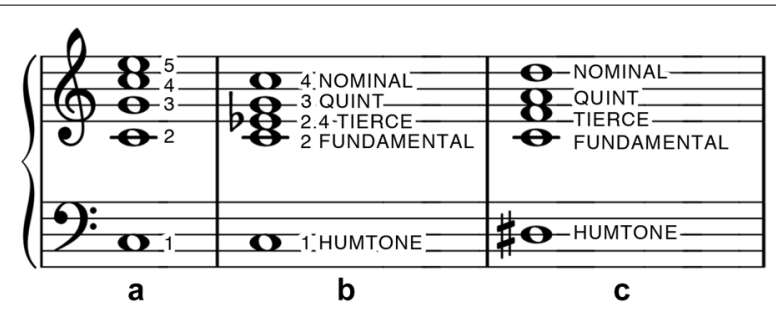

Fig. 1 Comparison of overtone series. The tuned carillon bell would be notated by the fundamental tone, $\boldsymbol{C}_{4}$. $\mathbf{a}$ The natural harmonic series, $\mathbf{b}$ a tuned carillon bell, $\mathbf{c}$ an untuned bell

A comparison of these partials in a tuned and untuned bell to the natural harmonic series is presented in Fig. 1. Unlike those of many instruments which are integer multiples of the fundamental tone, the most prominent overtones ('partials') of a well-tuned bell in equal temperament are 1:2:2.378:2.997:4 [34] (although most commonly rounded to 1:2:2.4:3:4 [35, 36]). Carillon bells are musically notated by their fundamental.

\section{Physical proportions}

For similar-shaped bodies (i.e. bells with similar profiles) made of the same material, the frequencies of corresponding modes of vibration are inversely proportional to the dimensions. A bell with twice the diameter of another should produce tones at half the frequencies (a musical octave below) of those produced by the smaller bell, while weighing eight times as much. This relationship was defined as the 'Line of Absolute Musical Proportion' [19]. What was observed in the work of the Hemony brothers (whose instruments were the pinnacle of bellfounding in the seventeenth century) was a deviation from the linear trend in the high treble bells: this was a compensation technique for weak audibility of smaller bells within the instrument. By increasing the wall thickness of the bell, decreasing height and diameter, and carefully tuning, a bell could produce the desired frequency with a volume comparable to mid-range bells of larger size. The following formula can be used to relate various dimensions of a bell [37]:

$$
M=c f D^{4}
$$

where the mass $M$ in $\mathrm{kg}$ (without a canon or any attachment pieces) is dependent on a profile constant $c$ in $\mathrm{kg} \mathrm{s}$ $\mathrm{m}^{-4}$, the fundamental frequency $f$ in $\mathrm{Hz}$, and the external diameter $D$ in $\mathrm{m}$. A higher constant indicates a heavier profile.

Due to the aforementioned inversely proportional relationship between the dimensions of similar-shaped bodies (e.g. bells with typical European profiles) and frequencies produced, another parameter used to discuss the proportions of bells is the $f D$ value in $\mathrm{m} \mathrm{s}^{-1}[38,39]$ : the product of fundamental frequency and diameter, an indicator of wall thickness. A higher $f D$ value indicators a thicker wall.

\section{Methods}

\section{Analysed carillons}

The two carillons studied are located in Toronto, Canada and are carillons typical of the musical range and weight for North American instruments incorporating twentieth century bells and mechanical actions.

\section{Soldiers' Tower Memorial Carillon, University of Toronto}

Soldiers' Tower was constructed in the 1920s as a memorial to the members of the University of Toronto community who fought and gave their lives in the First World War. The original instrument incorporated 23 original bells from the English firm Gillett \& Johnston (G\&J) in 1927 ([40], p. 271). The carillon was dedicated at a ceremony coinciding with the University's centenary ([41], p. 20). An additional nineteen bells cast by the American foundry Van Bergen were purchased in the 1950s, but the tuning of these newer bells did not match the original English bells, and were sold off to interested alumni. 28 replacement bells were later ordered from the Dutch firm Petit \& Fritsen (P\&F), and the composite 51-bell carillon was rededicated in 1976. Since its an inauguration, the carillon has been an integral component of significant events in the University's academic calendar, including the annual Remembrance Day Memorial service and convocation (graduation) ceremonies.

The tower was designed in a neo-gothic style and rises to a height of 142 feet. The belfry is enclosed on all four sides by thick stone walls, with screened openings representing approximately $35 \%$ of the total vertical surface of the enclosure (Fig. 2a). 


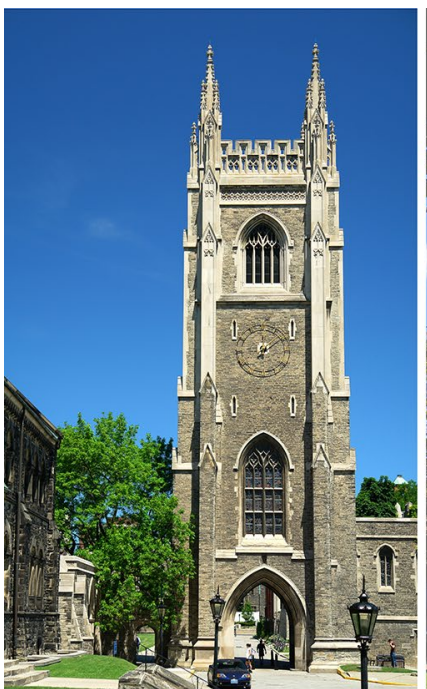

a

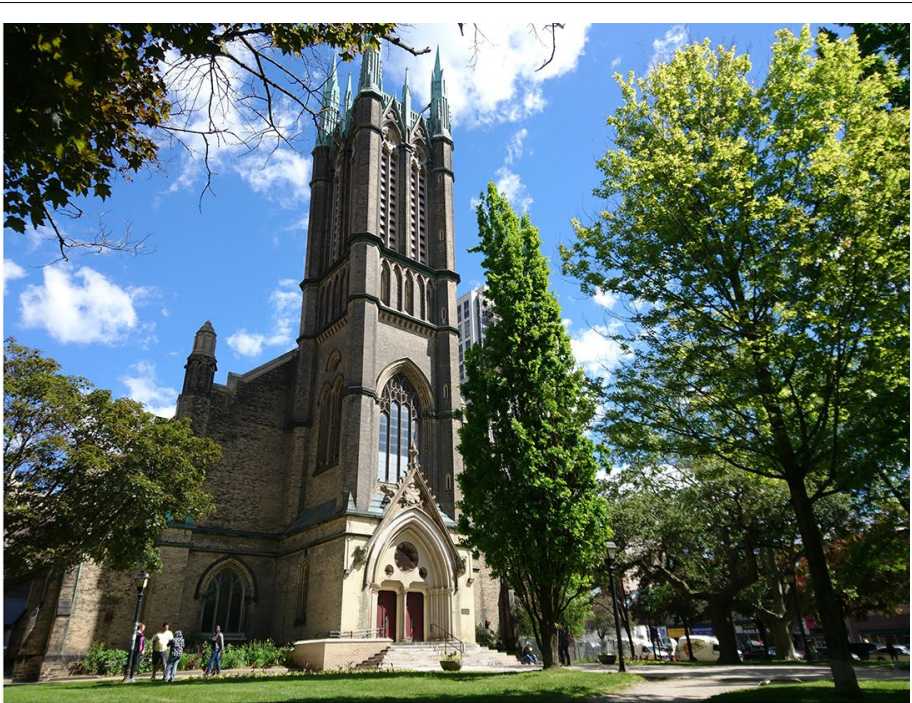

b

Fig. 2 External façades of the two carillon towers investigated. a Soldiers'Tower that houses the carillon, as seen from Hart House Circle. "Soldiers' Tower 2007" by V. Samarin is licensed under CC BY 3.0 (https://commons.wikimedia.org/wiki/File:Soldiers_Tower_2007.jpg). b The carillon tower of Metropolitan United Church, as seen from Queen St E

\section{Massey/Drury Memorial Carillon, Metropolitan United Church}

The tower of the Metropolitan United Church housed the first instrument of bells installed in North America that adhered to the modern-day definition of a carillon: 23 Gillett \& Johnston bells were purchased by Chester D. Massey and installed in 1922, although the tower dates back to 1872 [42]. These bells were tuned to A432, a reference frequency that Gillett \& Johnston employed for 'heavy' carillons; lighter instruments were tuned higher than A440 [43]. The initial expansion added 12 bells founded by Petit \& Fritsen that chromatically extended up from the highest original bell; these bells used A435 as a reference frequency. The final addition were 19 bells extending in a similar fashion cast by the French firm Paccard in 1971 that were tuned to match the reference tone of the original 23 bells, to form the 54-bell instrument currently housed in the tower. The instrument transposes down 3 semitones.

The tower is constructed of large stone masonry units, and includes an entrance hall for the church at ground level, a playing cabin beneath the belfry, and access to the latter elements. At $36 \%$, the belfry has a similar percentage of open space to that of Soldiers' Tower, but the panels are covered by wooden louvers, which are slats intended to keep the elements out and direct sound downwards to ground level (Fig. 2b).

At the time of data collection, the pedals were connected to the manuals with a non-traditional tensile string-based mechanism, guided by rollers (Fig. 3). This unconventional system is thought to be less sensitive than the transmission bar configuration more commonly employed in modern instruments, such as in Soldiers' Tower.

\section{Sampling}

Recordings were taken on weekend afternoons to minimise the effect of urban noise pollution caused by higher weekday vehicle traffic. This issue was most evident at the Metropolitan site, where the tower is located approximately $100 \mathrm{~m}$ from a major intersection with high rates

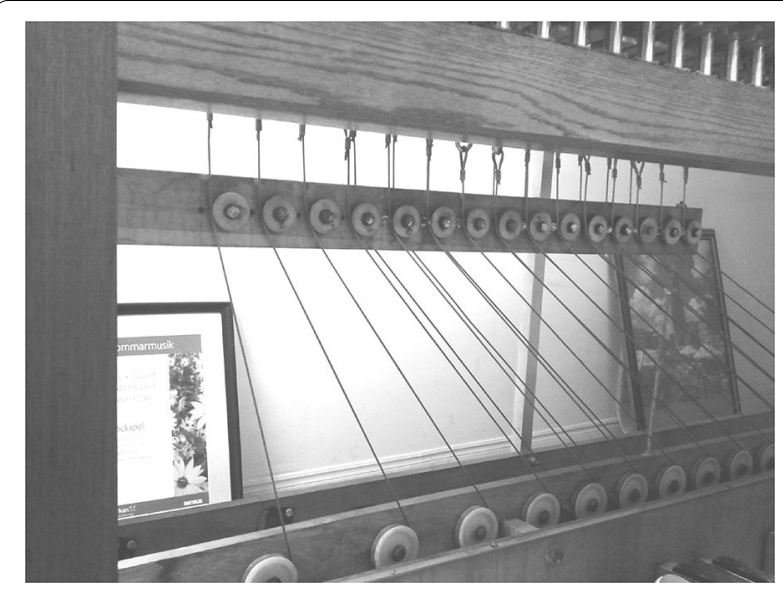

Fig. 3 The pedal board of the carillon at the Metropolitan United Church, which has an irregular connection of guiding roller wheels to connect the pedals to the keyboard batons 
of vehicle traffic, in addition to streetcars that contribute significant noise pollution. Soldiers' Tower is much more isolated and less susceptible to interference from vehicle traffic.

\section{Player input}

The carillonist was instructed to adapt their style of playing to the instruments, based on their experience with the varying weights and bells of each carillon. Three dynamic levels were tested on each bell: $p p, m f$, and $f$. These dynamics should be played at a force appropriate for the weight and frequency of each bell, based on experience and personal preference that ensures evenness of input across all instruments. Bells below $\mathrm{E}_{4}$ (4 semitones above 'middle $C$ ') were played with the pedals, as is common practice in carillon performance technique.

\section{Recording}

The pre-amp (485B36, PCB Piezoronics; Depew, NY), was connected to a personal laptop computer which accepted the microphone input via a $2.5 \mathrm{~mm}$ to $3.5 \mathrm{~mm}$ stereo jack adaptor. The microphone (377B02, PCB Piezoronics; Depew, NY) was suspended from a boomstand at a height of $1 \mathrm{~m}$ above the floor at a fixed point within the belfry, and angled down slightly. Although these measurements were taken in the belfry, a fixed measurement point is more closely aligned with the auditory experience of a listener at a fixed point further away. The sound meter was elevated slightly off a flat surface as proximal to the microphone as possible.

The microphone was operated with a foam ball windscreen, to minimise clipping effects from increased wind speeds. The laptop soundcard had a sampling frequency of $44.1 \mathrm{kHz}$ at 16-bit resolution. The microphone had a frequency range of 3.15 to $20000 \mathrm{~Hz} \pm 2 \mathrm{~dB}$.

The bells were recorded from lowest to highest in terms of musical note, and from softest to loudest musical dynamic marking. The samples from larger bells were recorded for up to $28 \mathrm{~s}$, and repeated if necessary to reduce any significant external sound sources, such as vehicle engines, in the first 7-10 s. This sampling time was gradually decreased to a minimum of $3 \mathrm{~s}$ for bells with shorter decay times, as determined by the carillonist's judgement by ear, for the sake of efficiency. The audio input was patched through to Audacity [44] and saved as bulk files per sampling session. Bell tones were rerecorded when necessary to ensure that the carillonist was satisfied with the dynamic level and major contributions of background noise were avoided. Each sample was exported individually to a .WAV file for analysis.

\section{Audio signal analysis}

The recorded samples varied in duration from approximately 3 to 28 s. A Discrete Fourier Transform was applied over the duration of each sample, resulting in frequency resolutions from 0.0359 to $0.3139 \mathrm{~Hz}$ for the largest and smallest bells, respectively. This approach enabled a high sensitivity for partials with especially low frequencies (prevalent in larger bells that were recorded for longer durations) while minimising the potential impact of ambient noise and other interference on the spectra of smaller bells with more rapid sound decay.

A two-stage peak detection algorithm was implemented:

- Stage 1: Identifying peaks within the practical range of the instrument. 3000 frequency peaks between 0 and $12 \mathrm{kHz}$; this upper bound was truncated from the detectable range $(22.05 \mathrm{kHz})$ based on the highest expected partial with an allowance for upper deviation.

- Stage 2: Identifying the first five partials for each bell. Selecting the most intense peak within \pm 200 cents $(\Phi)$ of the theoretical frequencies for each partial, equivalent to a frequency ratio (F.R.) range \pm 0.122 , or 2 musical semitones in equal temperament.

The measured frequency of each partial was compared to a reference frequency determined by the theoretical frequency ratios within a well-tuned bell with a typical European profile (see "Acoustic characteristics of bells" section). This was determined using the appropriate reference note (e.g. A435) based on foundry tuning logbooks and assuming equal temperament.

The raw audio samples were not altered or modified. Although noise reduction was considered, it was rejected primarily over concerns that lower-intensity partials that neared ambient background levels would be excluded from analysis. It was decided that, in order to truly reflect accurate carillon performance, the in situ analysis should consider partials within the context of urban ambient noise-a partial that is undetectable in the context of ambient noise levels indicates a performance and composition contribution significantly less important than partials with much greater intensities.

\section{Representing sensitivity to carillonist musical dynamic levels}

The sensitivity of summative intensity to changes in fundamental frequency (i.e. bell size) is analysed by creating resistive power-law models. It should be noted that these intensities are derived from the spectral 
analysis over the entire sample duration, and therefore do not represent decay times. This analysis fitted the intensities across the frequency range of each instrument for the three dynamic levels, according to:

$$
A=a f^{\left(-\frac{1}{k}\right)}
$$

where $A$ is the amplitude, or resultant intensity of the sample, $a$ is a power-law coefficient, $f$ is the fundamental frequency, and $k$ is a so-called resistive coefficient. These relationships were derived by using log-log plots of frequency versus intensity, which, if accurately modelled with a power-law relationship, yielded linearity. The slope of this relationship is equivalent to $k^{-1}$, from which the resistive coefficient can be calculated.

$$
\log (A)=\left(-\frac{1}{k}\right) \log (f)+\log (a)
$$

In this resistive power-law model, the coefficient $k$ is indicative of how significantly changes in fundamental frequency affect the intensity; they are only applicable for the instrument frequency ranges and detected intensities. As $k \rightarrow \infty$ there is little to no change in intensity sensitivity with changing frequency. In contrast, as $k \rightarrow 1$ there is infinitely strong sensitivity to different fundamental frequencies. This is used to evaluate how significantly the sound intensity levels change with decreasing bell size, and to enable comparison between musical dynamic levels.

\section{Results and discussion}

The bells were analysed with respect to their physical proportions, frequency deviations (tuning) from theoretical relationships, total and partial intensity (volume or audibility) and sensitivity to carillonist input.

\section{Bell dimensions}

An investigation of the dimensions of bells provided insight into design and production processes with implications for interpreting the acoustic measurements of the bells. Suitable data was available for the bottom two octaves of both instruments (founded by Gillett \& Johnston in 1922 and 1927, respectively) and the upper bells of Soldiers' Tower, founded by Petit \& Fritsen in 1976. Data for the remaining portions of the Metropolitan instrument were unavailable.

Although the instruments have similar musical ranges, their bells reveal foundry-specific variation in proportions.

Despite being founded only a few years apart, the two sets of Gillett \& Johnston bells have significantly

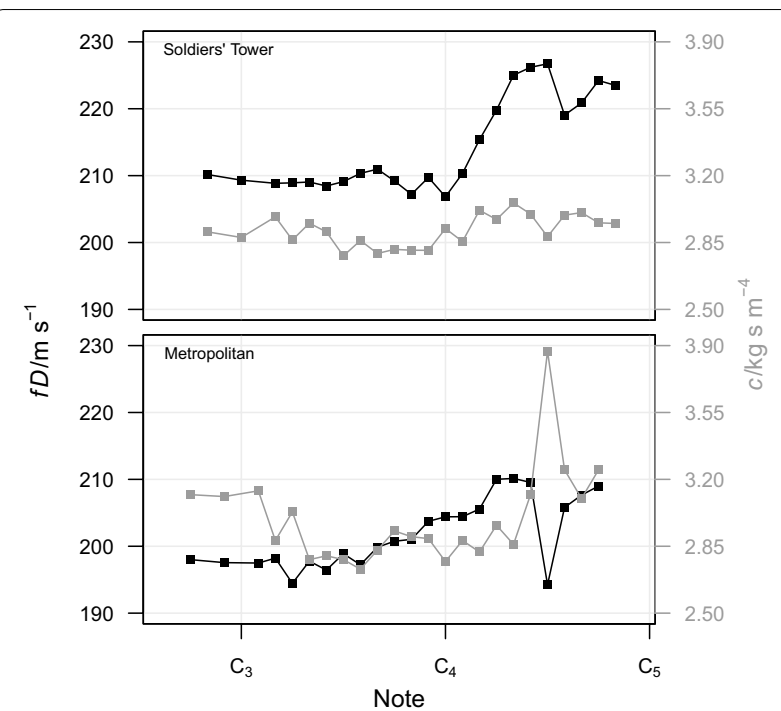

Fig. 4 Two indicators of proportion for the Gillett \& Johnston bells within the Metropolitan and Soldiers'Tower carillons: $f D$ (in black) and the profile constant c (in grey)

different proportions (Fig. 4). $f D$ is an indicator of wall thickness, while $c$ is a profile constant used to relate mass, fundamental frequency, and diameter. On average, the G\&J bells in Soldiers' Tower have thicker walls $f D=214 \pm 6.84$ (1 S.D.) than those in the Metropolitan carillon $f D=202 \pm 5.04$ (1 S.D.). However, the Metropolitan carillon has a higher (heavier) profile constant $(c=2.99 \pm 0.24,1$ S.D. $)$ than Soldiers' Tower $(c=2.91 \pm 0.08,1$ S.D. $)$. Both of these constants are greater than $c=2.8$ that Lehr recommends for general use. It has been proposed that G\&J based their early forays into founding well-tuned bells on on observations and designs of 19th century bells, which would be influenced by Grimthorpe's advocacy for bells with very thick walls and heavy profiles [45].

It is proposed that the higher variability of the $f D$ value and $c$ between individual bells within the Metropolitan carillon is, in part, likely related to these bells representing G\&J's first foray into producing bells for a carillon. The $F \sharp_{4}$ bell is particularly of note for its unusually low $f D$ value and high $c$ constant. It is possible that this bell was originally cast for another purpose and appropriated for inclusion within this instrument, which was common G\&J practice in the 1920s [46].

The profile constant for Soldiers' Tower is more consistent (as represented by a smaller standard deviation) than that of the Metropolitan carillon, which suggests it might have been part of the design process. Within Soldiers' Tower, the $f D$ value is very consistent in the bottom octave (up to $\mathrm{C}_{4}$ ) before sharply increasing. The causes 


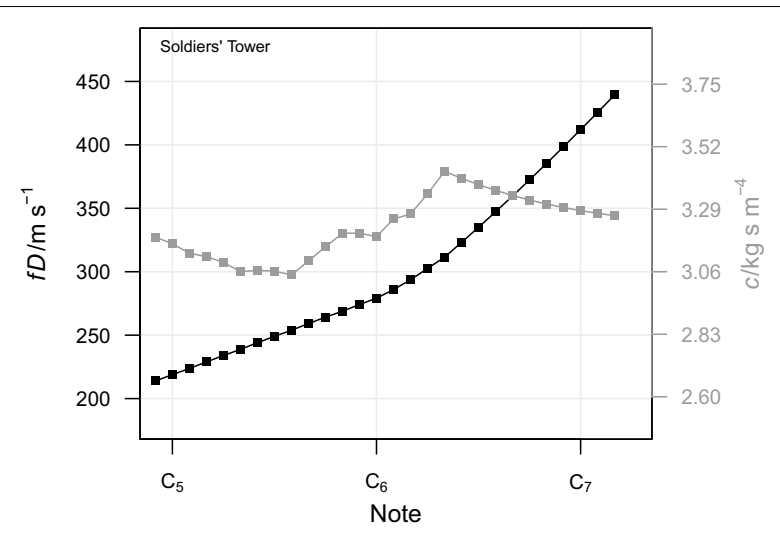

Fig. 5 Two indicators of proportion for the Petit \& Fritsen bells within the Soldiers'Tower carillon: fD (in black) and the profile constant c (in grey)

of these changes are uncertain, and require further investigation.

Twentieth-century carillon bells were not typically cast in direct proportion as is typical practice for swinging bells: the smaller bells have thicker walls and profiles to compensate for their smaller size in sound intensity and duration ( $f D$ from 214 to $439 \mathrm{~m} \mathrm{~s}^{-1}$ ). To this end, a single profile constant would not be suitable for the Petit \& Fritsen bells within the Soldiers' Tower carillon. This is exhibited by the linear trends in Fig. 5. This suggests that the use of $f D$ and related parameters were part of a systematic intentional design practice and is line with bellfounding practice toward the end of the twentieth century [39]. Of additional note is the peak in $c$ constants at $E_{6}$ followed by a consistent decrease for the highest octave of the instrument. While this could also be related to manufacturing practice, this would require further investigation.

\section{Frequency}

\section{Frequency deviations (bell tuning)}

The results of the frequency analysis of all 5 partials in both instruments is presented in Fig. 6. In general, the tuning of the Soldiers' Tower carillon is more consistent than its counterpart at Metropolitan: the deviations from theoretical frequency are smaller, and variation between measured and theoretical frequency are more gradual and consistent with decreasing bell size.

With decreasing bell size (i.e. with rising musical note), for the humtone, fundamental and nominal the difference between the measured partial frequency and the theoretical frequency changes from being negative (measured frequency flatter than the theoretical frequency) to being positive (measured frequency being sharper than the theoretical frequency). The same trend is seen to a less degree for the quint. This increasing proportionality represents a phenomenon knows as stretch tuning, a system in which notes are tuned increasingly sharp toward the the upper end of a keyboard instrument. Although typically applied to string percussion instruments such as pianos [47], Gillett \& Johnston were also known to apply this approach in their early carillons [48]. However, for the tierce the opposite behaviour is observed; that is, the difference between the measured partial frequency and the theoretical frequency changes from being positive to being negative. The trend is stronger in the Metropolitan G\&J bells. In the Metropolitan carillon, it is possible that Paccard was aware of this characteristic and implemented a similar method into their expansion of the instrument, to provide historical continuity to the instrument as a whole. However, this would require further investigation. In contrast, the Petit \& Fritsen extension of the Soldiers' Tower carillon did not incorporate this characteristic, instead opting for a 'neutral' approach in which the bells are tuned to a constant reference pitch without incorporating stretch tuning.

The measured frequencies of the humtone and the fundamental deviated between -20 and $+10 \notin$ from theoretical frequencies: this represents a level of consistency in tuning (in terms of variability relative to the other overtones) across the instruments. There is a significant negative deviation present in the bass bells (bell notes lower than $\mathrm{C}_{5}$ ) in both instruments. Above this, the humtone and the fundamental within the Soldiers' Tower bells hovered a few cents below expected (theoretical) frequencies, while the bells in the top octave of the Metropolitan carillon were measured to be higher than theoretical frequencies, with increasing deviations from theoretical frequencies up to the smallest bell in the instrument.

The measured nominal exhibit similar trends to those discussed in the humtone and fundamental, except that it was not detected in the audio samples for bell notes greater than $\mathrm{G}_{6}$ (except for a few bells in Soldiers' Tower). The quint exhibited the least apparent trend with fundamental frequency but is generally below theoretical frequencies. Although the partials are physically present in the bell, the quint was not detected in situ for bells in the top octave. It is proposed that these partials are absent from the analysis as they could be not detected above ambient noise levels. However, it is also possible that the clapper impact position on these bells is in the vicinity of the corresponding normal mode node.

The tierce has the most extreme behavior across both instruments: measured frequencies deviated from theoretical frequencies by $\pm 50 \mathrm{c}$, and, in general, proportional to bell size (smaller bells have measured 


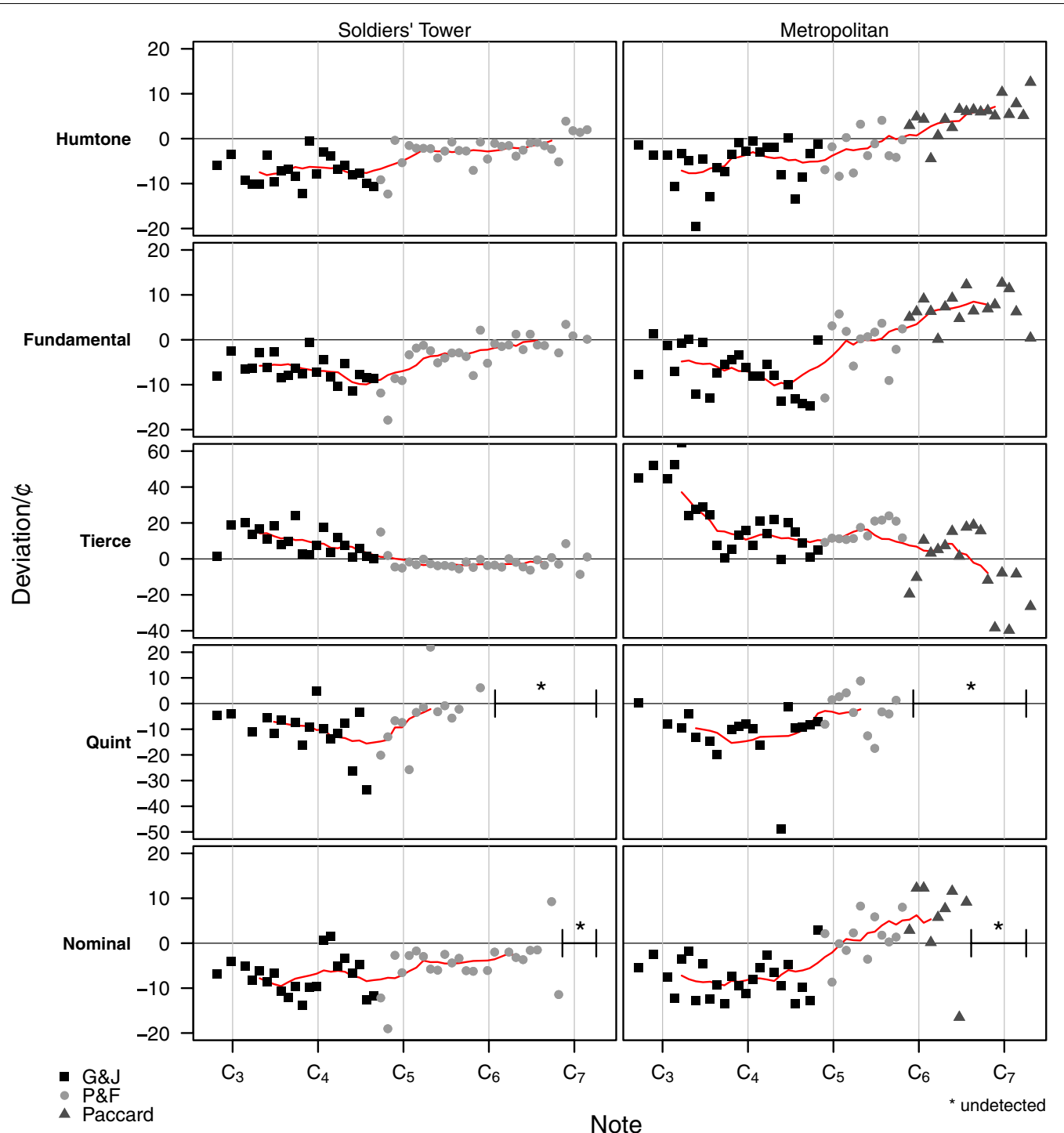

Fig. 6 Frequency deviations for the five primary overtones in the Metropolitan and Soldiers'Tower instruments. It is noteworthy that in both sets of bells the quint and the nominal were not detected for roughly the highest half and full octave of bells, respectively. The red line indicates a moving average $(n=10)$, indicating the general trend with decreasing bell size

frequencies closer to theoretical frequencies). The most significant tuning deviations from theoretical frequencies are observed in the largest bells of both instruments $(+25 /+50 \propto$ from theoretical frequencies), especially in the Metropolitan carillon. The erratic behavior (and generally positive deviations) of the tierce in both carillons is similar to characteristics observed in other Gillett \& Johnston instruments in which they aimed to tune internal minor thirds to the interval of a perfect third [48] (despite the potential clash of this with other bells within the instrument). This is demonstrated by the contrast in consistency of tierce tuning between the upper and lower portions of the Soldiers' Tower carillon, in which the bells produced by Petit \& Fristen have tierces consistently tuned to theoretical frequencies while those produced by G\&J are more varied.

The location of nodal meridians (tuning points) for each partial may cause some to be more susceptible to weathering and corrosion. For instance, the tierce meridian is located mid-way up the bell's waist, where the wall is quite thin. In contrast, the quint is located at one of the thickest points on the bell's wall, near the mouth (and clapper strike point). It is proposed that, because of these locations, the effects of weathering and corrosion may affect some partials more strongly than others, when their vibrational modes are located at thin portions of the 


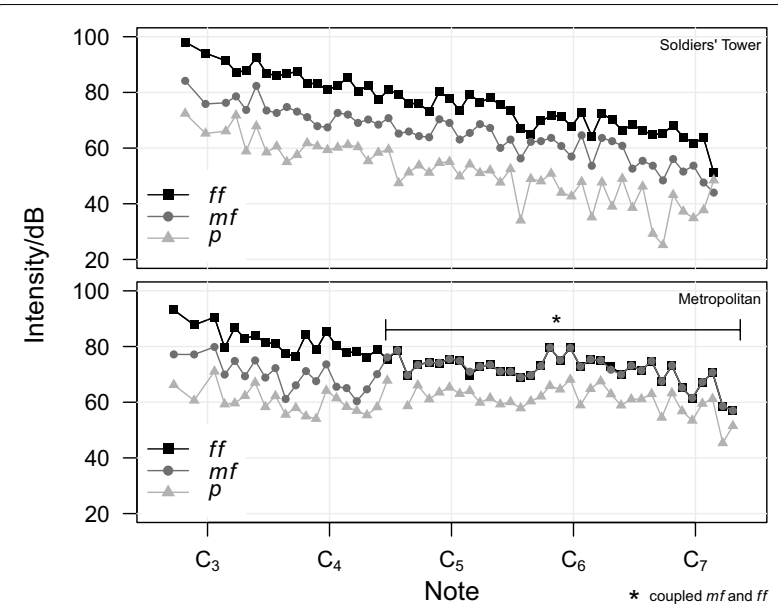

Fig. 7 The summative intensive of the first five partials of bells within the Soldiers'Tower and Metropolitan carillons at three musical dynamic levels

bell wall. The two previous examples support this claim: the measured tierces demonstrate the most variability while the quint is relatively stable in both instruments relative to theoretical frequencies.

The frequency deviations across the sets of Gillett \& Johnston bells provides evidence for a characteristic that has hitherto been discussed anecdotally. The tuning forks that the firm used to tune their instruments were flawed: they were generally flat (especially within the middle of octaves $\mathrm{C}-\mathrm{C}$ ). The outcome of this is that musical tones within these sets of bells close to $C$ will generally be tuned more closely to theoretical frequencies, but there is an oscillating trend toward the middle of octaves in which the middle of octaves $(\mathrm{C}-\mathrm{C})$ are more prominently tuned below theoretical frequencies. This is especially prominent in the upper-right panel of Fig. 6. So, although the tuning books reported the Soldiers' Tower carillon and the Metropolitan carillon to be tuned to references notes A435 and A432 respectively, in practice both instruments are tuned closer to A432 and A430, respectively.

\section{Intensity}

\section{Summative intensity}

The summative intensities of the five primary partials ranged from 25 to $100 \mathrm{~dB}$ for the Soldiers' Tower bells, while the Metropolitan bells had a smaller dynamic range of 45-95 dB (Fig. 7). The lower maximum for Metropolitan is likely due to the thinner profiles used in the Metropolitan carillon (see "Bell dimensions" section), despite its lower transposition compared to Soldiers' Tower. The samples taken of bells provided by Gillett \& Johnston (23 lowest-sounding bells in both instruments, bell notes approximately below $C_{5}$ ) have distinct separation between the three dynamic playing levels. The bells within the Soldiers' Tower carillon show a consistent decrease proportional to bell size, while the Metropolitan carillon has a smaller and less distinct dynamic range. Also of note is the coupled $m f$ and $f f$ intensities for the upper range of the Metropolitan carillon. This implies that the carillonist is limited by the mechanism to create a contrast between $m f$ and $f f$ dynamic levels.

The resistive power models are presented in Fig. 8. A highly linear fit (represented by high $\mathrm{R}^{2}$ values) implies a consistent decrease in intensity with decreasing bell size produced by the carillonist input. The carillon of Soldiers' Tower exhibits much more consistent behaviour for all three dynamic levels, as represented by $\mathrm{R}^{2}>0.69$. In contrast, only the $f f$ playing level of the Metropolitan followed a power-law relationship with a commensurate $\mathrm{R}^{2}=0.67$; the other two dynamic levels had very low $\mathrm{R}^{2}$ values so these models were discarded. Put another way, it is impossible to discuss the $k$ coefficients as the relationship was not sufficiently consistent across the instrument range. In general, a louder dynamic input level yielded a narrower range of resultant intensities, i.e. the carillonist had less control of the output sound intensity from the carillon action.

$k$ (in this case, the slope of the fitted line in red in Fig. 8) is indicative of the sensitivity of intensity to changes in fundamental frequency. From the values of $k$ in Fig. 8, it can be seen for the Soldiers' Tower carillon that the sensitivity to carillonist input decreases with playing dynamic; put another way, intensities at a $p p$ vary more in intensity than at $m f$ and $f f$ levels. In contrast, the Metropolitan carillon at a ff dynamic level is less sensitive than the Soldiers' Tower carillon at any musical dynamic level, while the other levels did not sufficiently-consistent relationships to discuss $k$ coefficients.

\section{Relative partial intensity}

The partials, in general, followed an established order of audial prominence, relative to one another: the humtone, the tierce, the fundamental, the nominal, and the quint. Although the tierce is quite prominent, its intensity is offset by the combined tonality of the humtone, fundamental and nominal-which stresses the importance that these octave overtones must be in accordance with one another in the internal tuning of each bell. Figure 9 shows the intensity of each partial is compared to the intensity of its respective fundamental frequency, so that their relative prominence across the instrument ranges can be discussed.

The humtone hovers around the same intensity as the fundamental frequency until $\approx \mathrm{D} \sharp_{5}$, at which point it increases prominence to $10-20 \mathrm{~dB}$ greater than the fundamental frequency. 


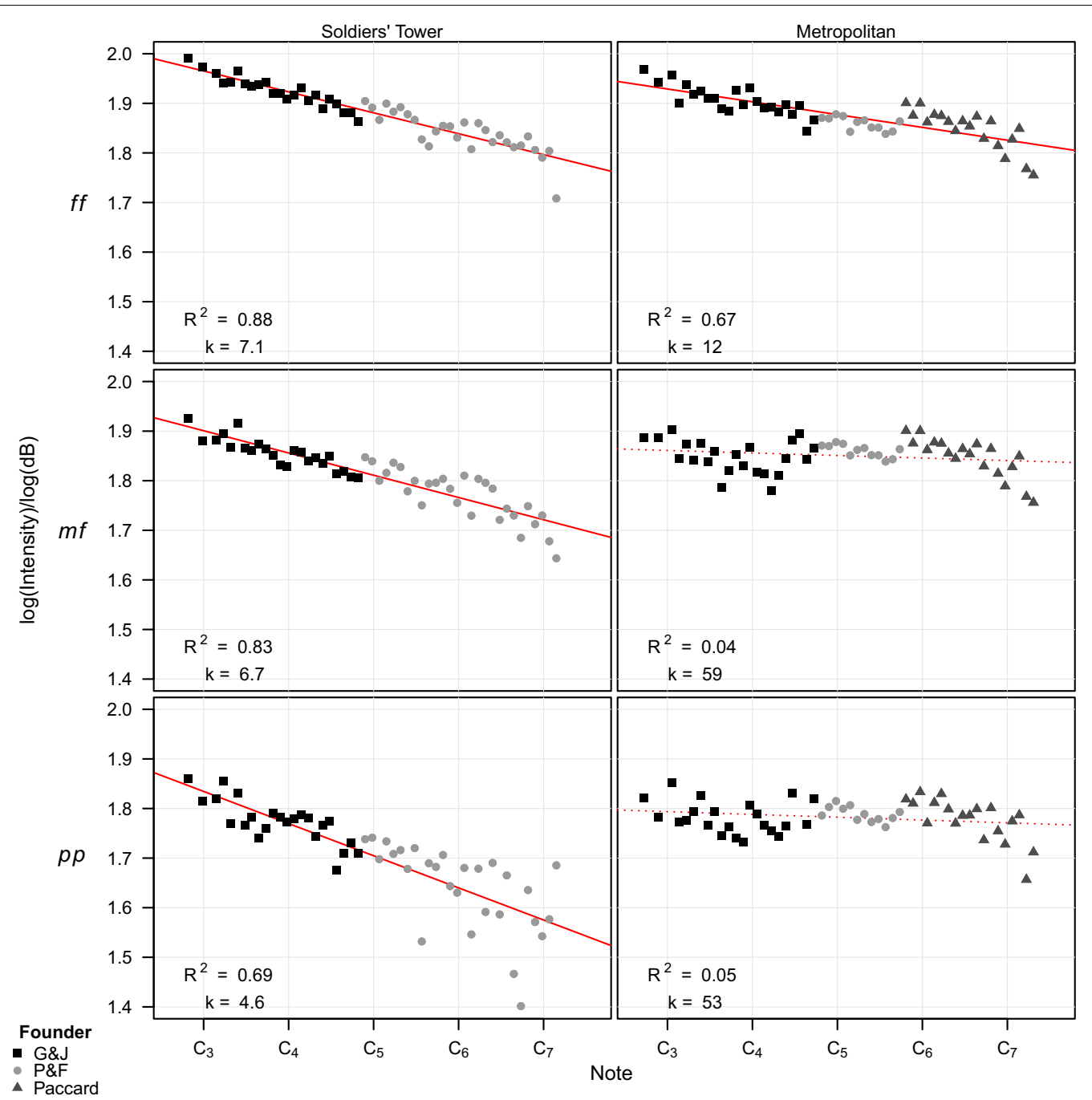

Fig. 8 Summative bell intensity (total of the five main partials) log-log plots for Soldiers'Tower and Metropolitan bells at $p p, m f$, and ff musical dynamic levels

The tierce is more stable than the humtone, remaining equally prominent to the fundamental over the instruments' entire frequency ranges. The only exception to this is a noticeable increase in the Metropoli$\tan$ Paccard bells (upper range), which peak at $+20 \mathrm{~dB}$ intensity relative to the fundamental frequency.

The quint is very weak and inconsistent as compared to the other partials. It can best be described as a loose cluster centered around $-20 \mathrm{~dB}$ relative to the fundamental frequency.

The nominal is also quite strong in the lower frequencies ranges, before tapering off to levels between -10 and $-20 \mathrm{~dB}$ relative to the fundamental. Given the extreme frequency ranges of these overtones $(7-10$
$\mathrm{kHz}$ ), it is not surprising that these partials do not make a significant contribution to the bell's overall tone quality, as they approach the limit of human detection.

The relative intensity of a partial is partly dependent on the clapper impact position. However, this was not studied due to access limitations.

\section{Partial sensitivity}

Resistance power-law models were applied to the five primary partials, which produced better-fitting resistive models $\left(\mathrm{R}_{a v}^{2}=0.64\right)$ for the Soldiers' Tower carillon as compared to Metropolitan $\left(\mathrm{R}_{a v}^{2}=0.33\right)$. These $\mathrm{R}_{a v}^{2}$ values demonstrate that the prominence of the overtones within the Soldier's Tower carillon are more 


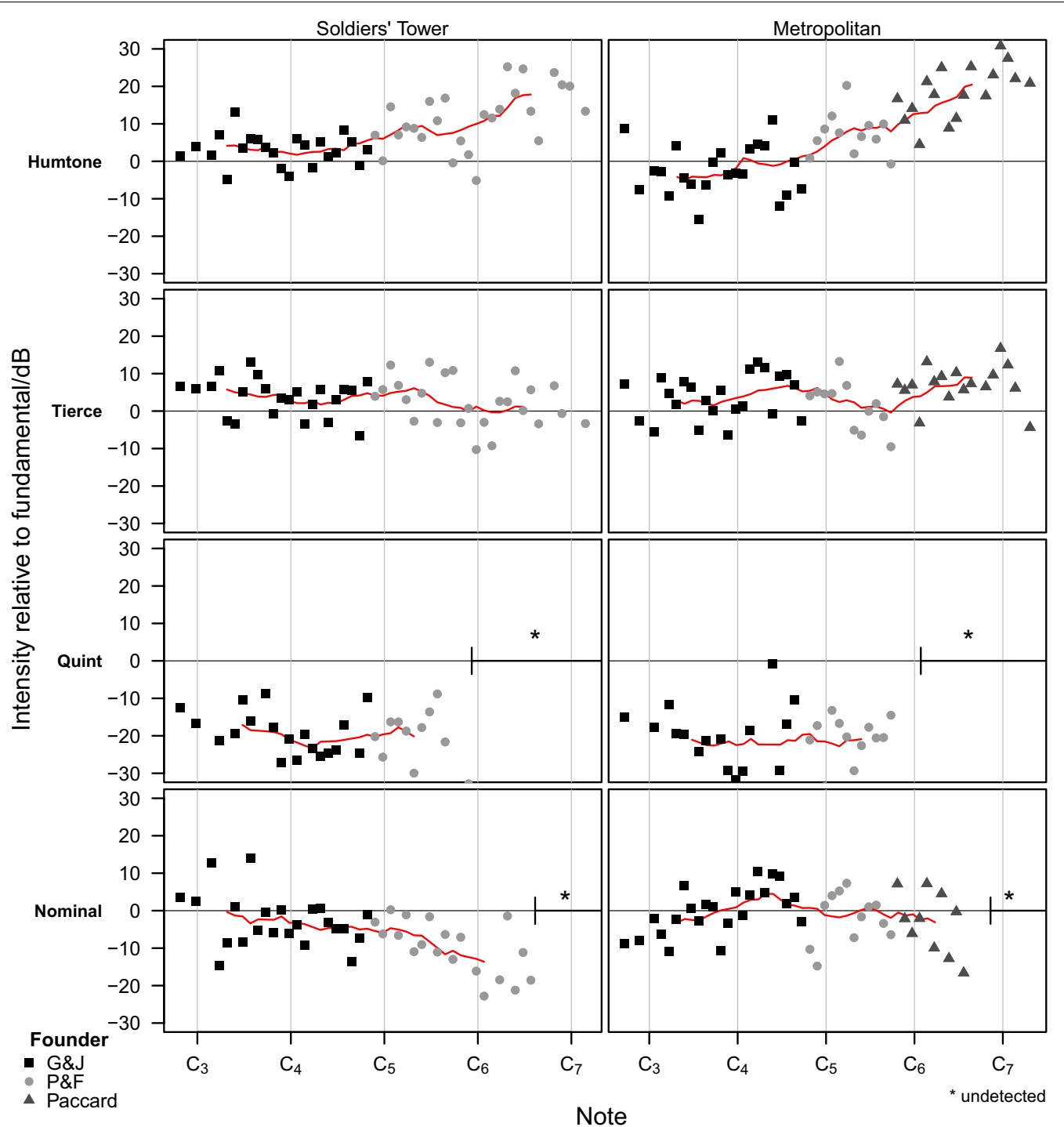

Fig. 9 Partial intensities relative to the fundamental $(F . R .=2.000)$ overtone for Soldiers'Tower and Metropolitan bells. The intensity deviations were averaged across all three dynamic levels

consistently related to carillonist input across the range of the instrument than those in the Metropolitan carillon (Fig. 10).

The intensity (or prominence) of the Metropolitan humtone behaves inversely to the fundamental frequency (as represented by $k$ values $<0$ ). This means that bells of smaller size are producing a more intense partial than the larger bells in the set. One possible explanation is the production techniques of P\&F and Paccard in the upper portions of the instrument that may contrast those of the original G\&J bells. One exception to the overall behaviour of the Metropolitan is the fundamental partial, which exhibits similar power-law behaviour and $k$ values to the Soldiers'
Tower samples, demonstrating similar consistency across the range of the instrument.

The tierce and the quint of the bells within the Soldiers' Tower carillon exhibit the smallest variation in resistive coefficients: regardless of musical dynamic level, the change in prominence across the instruments range is very similar. The nominal has the lowest average resistive coefficient, demonstrating that its intensity is the most sensitive across the range of the instrument.

\section{Discussion}

Although the greatest heritage importance is typically placed on the bells in a carillon, the results presented herein demonstrate the importance of the mechanical 


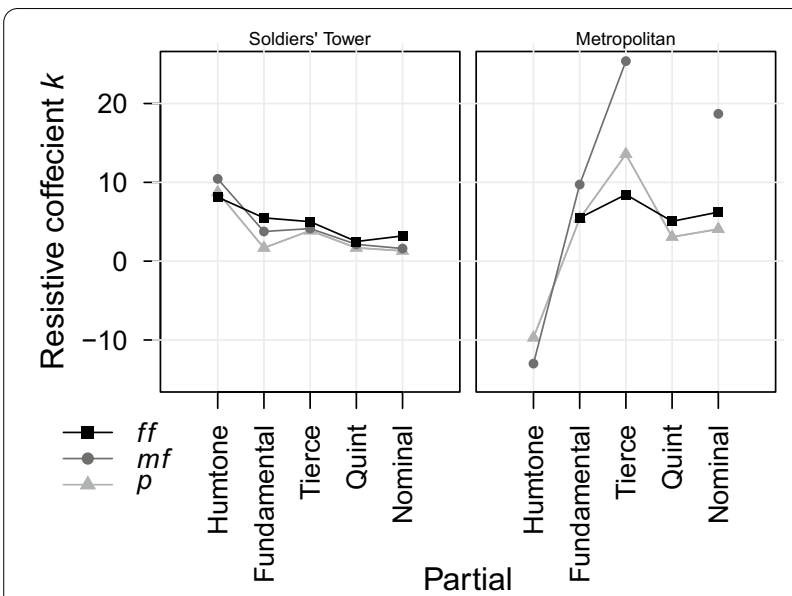

Fig. 10 Resistive coefficients (k) for Soldiers'Tower and Metropolitan bells. As represented by $k$ values closer to 1 than its Metropolitan counterpart, the transmission system of the Soldiers'Tower allows for a greater range of dynamic response across the instruments range and higher contrast between dynamic levels

action as part of the holistic system of the carillon as a musical instrument. The mechanical action is an important control on the sensitivity and regularity of the sound intensity produced by the input from the carillonist. This has implications for how carillon music is arranged and composed. Figure 7 shows that, due to the mechanical action of the Metropolitan carillon, there is no discernible difference in the audio intensity produced at the $m f$ and $f f$ dynamic levels. The practical result of this is that, if written music is prepared to be suitable for a wide range of instruments, the variability of age, consistency, and quality of the mechanical action should be considered. So, if a distinguishable musical level is required for artistic effect, a sharper contrast of musical levels (such as $f f$ and $p p$ ) should be used to produce this effect. A relevant example would be the use of 'terraced dynamics' [49] in baroque music, in which repetition is employed with distinct musical dynamic levels to produce an 'echolike' effect. Further, different phases of work on the carillon manifest as variations in the musical sensitivity of the instrument. For example, Figs. 7 and 8 show that within the Metropolitan carillon there are distinct trends of relative partial intensity depending on the bellfounder (which correspond to different phases of renovation work on the carillon). While both the Gillett \& Johnston lower and Paccard upper sections of the instrument show weakly decreasing variations of summative bell intensity across their ranges, the Petit \& Fritsen middle section is relatively constant across it's range. Whether intentional or not, the mechanical action employed by Petit \& Fritsen in this instrument has reduced the natural decrease of the audio intensity in the middle range of the instrument, producing a more even intensity output. However, it is unclear to the extent to which this result would apply to other carillons by the same founder or different eras of construction.

The original bells of the Metropolitan carillon are mounted directly above the playing cabin, while the second set of bells was placed above these. The tower is quite narrow, and there is little room to manoeuvre around the bell frame. To facilitate access for maintenance, the 1971 Paccard bells were installed in the space around the original base bells. The decreased length of parts involved with playing these bells increases dynamic sensitivity, but the proximity to the playing cabin is quite uncommon for bells in this range. To this end, the carillonist hears a dynamic bias towards these bells, that is not representative of the sound at exterior ground level. This likely exacerbates the player's ability to gauge different musical dynamic levels at their close proximity to the upper bells in the playing chamber.

This demonstrates an important point: the properties of carillon installations of bellfounding firms have changed significantly over time. This is most prominently seen in the contrast of the Petit \& Fritsen sections of the instruments. The mid-section of the Metropolitan carillon shows more strongly deviating measured frequencies from theoretical frequencies (Fig. 6) than the corresponding range of Soldiers' Tower. While it is possible that part of this is due to the application of stretch tuning, it seems unlikely that this technique would have been applied in the Metropolitan carillon for an extension of only one octave (13 bells) within that particular range of musical notes. While that installation was in 1960, by 1976 when Petit \& Fritsen installed the upper-half of the instrument in Soldiers' Tower, the partials show more consistent variation in measured frequencies from theoretical frequencies (especially the humtone and tierce); there is no evidence of stretch tuning to match the technique employed by Gillett \& Johnston in their early installations of four musical octaves or greater. Further investigation is required to produce a more rigorous understanding of the development of founding and installation practices of twentieth-century bellfounding firms.

From heritage and artistic perspectives, there are several considerations of what makes a 'good' carillon. While there is a broad consensus that bells sounded with other bells (such as in carillons) need to be 'well-tuned' [50], what is 'good enough' is yet to be determined. While the aforementioned range of typical human detection might be used as an upper limit of acceptable tuning constraints, there are other arguments to be made for wider variation. For example, when Mechelen (the centre of revitalised carillon culture in the twentieth century) installed a new carillon in the tower to complement 
the historic instrument, there was mixed public opinion about whether the new instrument was preferable [51]. Although the new carillon was an incredible feat of engineering with precisely-tuned bells, many residents found the change of soundscape resulted in a loss of nostalgia. Thus, although the instrument afforded a higher level of artistic potential, the public opinion varied from that of a well-trained musician. The early twentieth-century 'authoritative' expert opinion was that the partials of a bell should be tuned to within 1 cycle per second $(1 \mathrm{~Hz})$ and that the use of tuning forks, representing mechanical precision used to determine the quality of bell tuning, mattered more than human perception of the quality of a bell (see, for example, the case of the Coventry Cathedral bells in 1926 [52]). The contribution of this study to defining a 'good' carillon have implications for the growing interest in more accurate and precise digital synthesis of bell tones [53, 54], which is becoming increasingly prevalent in multimedia music experiences [55]. Further investigation is needed of public perception of variations in bell tuning, as well as an exploration of material authenticity in carillon restoration projects.

The irregular pedal mechanism in the Metropolitan carillon has not significantly impacted the sensitivity to the carillonist's musical dynamic level. This was likely mitigated by the substantial differences in sound intensity produced by larger bells as a result of their changing proportions, so the mechanism in this range is of secondary importance.

A limitation of this study is the method of audio sample collection. As all recordings were taken from a location within the belfry, they do not accurately represent the experience of a listener from ground level. Typically, it is recommended to listen to carillons from distances of at least 50 to $100 \mathrm{~m}$, depending on the instrument and site context. However, obtaining consistent audio samples at a location near to the carillon is made difficult by several factors, such as varying wind direction (impacting how the sound travels) and interference from other noise sources. One mitigation technique is to take samples during the nighttime, when interference is mitigated, although further logistical and administrative barriers might present themselves with this approach. As well, the impact of local context (such as adjacent buildings, especially large open façades and corners), can significantly impact the audial experience. Further work should consider carillons in a complex local setting, and evaluate acoustic properties of the instrument in several locations to explore this effect. There may also be the opportunity for advanced techniques such as acoustic modelling to evaluate this [56] that would build on existing modelling that has studied the relationship between bells and their urban context in a historical perspective [57].

\section{Conclusion}

Various aspects of two twentieth-century carillon bells and transmission systems were compared, with an emphasis on identifying in situ characteristics. Audio samples of each bell were taken at three musical dynamic levels $(p p, m f, f)$. Spectral analysis demonstrated the great variation between sensitivity to player input and partial intensity. Resistive-power law models represented how the sensitivity to a carillonist's musical dynamic level is variable over the range of the instruments and depends on the characteristics of the bells and the installation.

This study demonstrates the complex attributes of the carillon, including:

- variation of foundry production techniques, as well as how these change over time;

- the acoustics of bells within the context of musical dynamics and carillonist perception; and

- the importance of considering the carillon as a holistic musical system.

The discussion that follows explored the important ramifications of these results for carillonists, composers, and arrangers of music for carillon. Developing the understanding of in situ carillon acoustics and physical attributes supports the ongoing development of the musical and technical capabilities of the carillon, as well as deeper understanding of carillons as heritage that informs their conservation and management.

\section{Abbreviations \\ G\&J: Gillett \& Johnston Bellfoundry; P\&F: Petit \& Fritsen Bellfoundry; FR: Frequency ratio.}

\section{Acknowledgements}

The author is personally grateful to Roy Lee for offering his services as the performing carillonist for these experiments; and to Willy Wong, Brian Wang and Jennifer Tsang of the University of Toronto's Institute of Biomaterials \& Biomedical Engineering and Edward S Rogers Sr. Department of Electrical and Computer Engineering for providing instrumentation and logistical support. The manuscript was also improved by early feedback provided by Bert Augustus and Luc Rombouts.

\section{Authors' contributions \\ All contributions were from the sole author. The author read and approved the} final manuscript.

\section{Funding}

There is no funding associated with this publication.

Availability of data and materials

The data and materials for this publication are unavailable.

Competing interests

The authors declare that they have no competing interests.

Received: 4 September 2020 Accepted: 7 January 2021

Published online: 03 February 2021 


\section{References}

1. World Carillon Federation. Statues. 1:3.2; 2011. http://www.carillon.org/ eng/fs_orga.htm.

2. UNESCO. Belfries of Belgium and France. 2005. http://whc.unesco.org/en/ list/943/.

3. UNESCO. Convention for the safeguarding of the intangible cultural heritage. Paris: UNESCO; 2003.

4. UNESCO. Decision of the Intergovernmental Committee: 9.COM 9.B.1. https://ich.unesco.org/en/decisions/9.COM/9.B.1.

5. $\mathrm{Ng}$ T. A new history of the carillon. Keyboard Perspect. 2015;8:185-94.

6. Schneider A, Leman M. Sound, pitches and tuning of a historic carillon. Cham: Springer International Publishing; 2017. p. 247-298. https://doi. org/10.1007/978-3-319-47292-8_9.

7. Watson JR. Artifacts in use: the paradox of restoration and the conservation of organs. Villanova: OHS Press; 2010.

8. Vaiedelich S, Fritz C. Perception of old musical instruments. J Cult Herit. 2017;27:S2-S7.

9. Price P. Elements of carillon music. GCNA Bull. 1947:II(1):9-27.

10. Price P. The decalogue of transcription for carillon. GCNA Bull. 1961;XIV:55.

11. Allard E. Essay on composition. GCNA Bull. 1984;XXXIII:12-5.

12. Barnes R. Personal criteria for composing and arranging for the carillon. GCNA Bull. 1995;XLIV:22-9.

13. Brink J. Composing for carillon. 2017. https://nmbx.newmusicusa.org/ composing-for-carillon/.

14. Gouwens J. Composing for the carillon: recommendations and examples; 2009. http://carillon.vrvisuals.com/COMPCARVID.pdf. Includes audiovideo demonstration. http://carillon.vrvisuals.com/movie.html.

15. Semowich C. Carillon music: suggestions for composing for carillon. 2013. http://www.utexas.edu/tours/mainbuilding/carillon/.

16. Carillon Society of Australia. Composing for the Australian carillons. 2010. http://www.carillon.org.au/composing/composing.pdf.

17. Guild of Carillonneurs in North America. The 1960 congress. GCNA Bull. 1960;XIII(2):ii-iii, 1-20.

18. Gerken A. Perspectives in creating music for the carillon. GCNA Bull. 1995;XLIV:15-211.

19. Bigelow AL. The acoustically balanced carillon. Princeton: School of Engineering, Princeton University; 1961.

20. van Heuven EW. Acoustical measurements on church-bells and carillons. Ph.D. Thesis. Delft University of Technology, Delft, Netherlands; 1949.

21. Rossing TD. Acoustics of bells. Benchmark papers in acoustics. New York: Van Nostrand Reinhold; 1984a.

22. Canfield-Dafilou EK, Werner KJ. Modal audio effects: a carillon case study. In: Proceedings of the 20th international conference on digital audio effects, Edinburgh, UK, September 5-9, 2017; 2017. p. 247-54.

23. Debut V, Carvalho M, Soares F, Antunes J. Reverse engineering techniques for investigating the vibro-acoustics of historical bells. In: International conference on acoustics and vibration, Hammamet, Tunisia, 19-21 March 2018. New York: Springer; 2018. p. 218-26.

24. Lehr A. The system of Hemony-Carillons tuning. Acustica. 1951;3:101-4.

25. Macoska P. Keyboard standards. 1970. Original published in GCNA Bulletin, 1970. Revised 1981. http://www.gcna.org/documents/keybo ard-standards.pdf.

26. Elphick G. The craft of the bellfounder. Bognor Regis: Phillimore \& Co.; 1988.

27. Lehr A. Campanology textbook (English translation). GCNA Bulletin. 2008;LIV:1-111. Translated by Schafer K. Original Dutch version: Leerboek der campanologie, Asten. Netherlands: Nationaal Beiaardmuseum; 1976.

28. Howard HM. The story of bells and bell music. High Fidel News. 1957;2(2):154.

29. Goldsmith W. Impact. London: Arnold; 1960.

30. Fletcher NH, McGee WT, Tarnopolsky AZ. Bell clapper impact dynamics and the voicing of a carillon. J Acoust Soc Am. 2002;111(3):1437-44.
31. Rossing TD, Perrin R. Vibrations of bells. Appl Acoust. 1987;20(1):41-70.

32. Rossing TD. The acoustics of bells: studying the vibrations of large and small bells helps us understand the sounds of one of the world's oldest musical instruments. Am Sci. 1984;72(5):440-7.

33. Perrin R, Charnley T, DePont J. Normal modes of the modern English church bell. J Sound Vib. 1983;90(1):29-49.

34. Perrin R, Swallowe GM, Charnley T, Marshall C. On the debossing, annealing and mounting of bells. J Sound Vib. 1999;227(2):409-25.

35. Boutillon X, David B. Assessing tuning and damping of historical carillon bells and their changes through restoration. Appl Acoust. 2002;63(8):901-10.

36. Schoofs AJG, Roozen-Kroon PJM, van Campen DH. Optimization of structural and acoustical parameters of bells. In: 5th symposium on multidisciplinary analysis and optimization; 1994. p. 1167-80.

37. Lehr A. A general bell-formula. Acustica. 1952;2:35-8.

38. Roozen-Kroon PJM. Structural optimization of bells. Ph.D. Thesis. Technische Universiteit Eindhoven. 1992.

39. Lehr A. Partial groups in the bell sound. J Acoust Soc Am. 1986;79:2000-111.

40. Friedland ML. The University of Toronto: a history. Toronto: University of Toronto Press; 2013

41. University of Toronto. A record of proceedings at the celebration of the centenary of the University of Toronto, 1927: published by authority of the Board of governors of the University. Toronto, Canada: The University of Toronto Press; 1929.

42. Metropolitan United Church. Bells that made history. Supplied by J. B. Slater. 2013 (Brochure)

43. Slater JB. Personal correspondence. Sent and received on June 25, 2013 (Email)

44. Audacity. Audacity. http://www.carillon.org/eng/fs_orga.htm.

45. Hibbert B. A history of Taylors in bell sounds. The Ringing World. 2018. http://www.carillon.org/eng/fs_orga.htm.

46. Johnston G. Tuning books. City of Croydon Archive, AR1/1/8.

47. Martin DW, Ward W. Subjective evaluation of musical scale temperament in pianos. J Acoust Soc Am. 1961;33(5):582-5.

48. Augustus B. The carillon as a concert instrument. In: Proceedings of the 12th world carillon congress, Springfield, IL, USA, July 2000; 2000. p. 1-12.

49. Rangel-Ribeiro V. Baroque music: a practical guide for the performer. Mineola: Courier Dover Publications; 2016.

50. Hibbert B. The tuning of bells. http://www.carillon.org/eng/fs_orga.htm.

51. De Rombouts L. beiaard: Een politieke geschiedenis. 'Het Mechels wonder': De beiaard tussen cultus en citymarketing, vol. 9. Leuven: Leuven University Press; 2009. p. 147-170.

52. Hibberts B. Coventry bells enquiry. 2004. Online, Reprints from "The Ringing World" January 15th and 22nd, 1926. https://www.hibberts.co.uk/ coventry_court.htm.

53. Lee D. A thousand bells: acoustical implementation of bell spectra using the finite element method and its compositional realization. Ph.D. Thesis. University of Illinois at Urbana-Champaign. 2020.

54. Rau M, Das O, Canfield-Dafilou EK. Improved carillon synthesis. In: Proceedings of the 22 nd international conference on digital audio effects, Birmingham, UK, September 2-6, 2019; 2019. p. 1-8.

55. Hamilton R, Platz C. Gesture-based collaborative virtual reality performance in carillon. In: Proceedings of the 2016 international computer music conference; 2016. p. 337-340.

56. Hornikx M. Acoustic modelling for indoor and outdoor spaces. J Build Perform Simul. 2015;8(1):1-2.

57. Atkinson N. Mapping space, sense, and movement in Florence: historical GIS and the early modern city. Seeing sound: mapping the Florentine soundscape. Abingdon: Routledge; 2016. p. 149-168. 